\title{
Shiga toxin-producing Escherichia coli infection in South India
}

Infection with Shiga toxin-producing Escherichia coli (STEC) is a recognized cause of diarrhoeal illness, and can be followed by life-threatening complications such as haemorrhagic colitis and/or haemolytic uraemic syndrome (HUS) (Tozzi et al., 2003). The key virulence factors associated with complications are Shiga toxins, Stx1 and Stx2, with variants of each type, and the products of the locus of enterocyte effacement (LEE) pathogenicity island, which encodes the proteins critical for intimate adhesion of bacteria to enterocytes via formation of attaching and effacing lesions

(Donnenberg et al., 1993). Infection with strains producing at least one Stx2 variant are most closely associated with severe complications (Boerlin et al., 1999).

In the developed world, large STEC outbreaks are frequently caused by ingestion of foods that have been contaminated at the production site and subsequently distributed widely (Uhlich et al., 2008). In contrast to the developed world, in India little is known about human STEC epidemiology or the human burden of disease due to STEC infection. Multiple reservoirs for STEC exist in India, including healthy cattle and goats, calves with or without diarrhoea, dairy cows and water supplies (Khan et al., 2002). Despite this, studies of the causes of human diarrhoea in India have indicated a non-detectable to low prevalence of STEC-associated disease (Dhanashree \& Mallya, 2008).

In this study, we report the prevalence of STEC in a hospitalized population of South Indian children with diarrhoea and controls. Between 2003 and 2006, 392 children aged less than or equal to 5 years admitted to the hospital with diarrhoea were recruited after obtaining informed consent from the parent/guardian.

Diarrhoea was defined as the passage of three watery stools in a $24 \mathrm{~h}$ period and a diarrhoeal episode was defined as at least 1 day of diarrhoea preceded and followed by 2 or more days without diarrhoea, as previously described in this study population (Monica et al., 2007). Ninetynine children of similar age admitted to the hospital for non-diarrhoeal causes between July and September 2004 were included as controls. The collected stool samples were stored as aliquots at $4{ }^{\circ} \mathrm{C}$. DNA was extracted from these stool samples using the QIAamp stool DNA minikit (Qiagen). PCR was performed on the extracted DNA to detect stx1, stx2 and eae of STEC using previously published primers (Vidal et al., 2005). STEC strains were isolated from PCR-positive stools, and colony multiplex PCR was carried out to detect the presence of the novel AB5 subtilase cytotoxin by amplifying the $s u b A$ gene, using previously published primers (Paton \& Paton, 2005).

stx genes were detected in 9/392 cases. Table 1 shows that the STEC strains isolated from children with diarrhoea in South India were mainly stx1-positive (7/9). The marker for LEE (eae) was present in 4/9 STEC strains from diarrhoea cases; none had $s u b A B$. Interestingly, 2 of 99 controls were STEC-positive. One of the isolates was stxl-and eae-positive; the other was stx2- and eae-positive.

In this study, we found a low prevalence of STEC in preschool-aged children admitted to hospital with diarrhoea $(2.3 \%)$ and an equivalent $(2 \%)$ asymptomatic STEC carriage rate in controls, suggesting that STEC may not have been the causative agent in those children with diarrhoea from whom it was recovered. A similar prevalence of eae-positive STEC strains was found in both groups. Over half of the strains found in patients with diarrhoea were eae-negative stx1-producing only $(5 / 9)$; infection with these strains is thought to carry relatively lower risk for HUS than infection with those with the LEE and $s t \times 2$.

To our knowledge, this study is the first in India to use a control group of community-derived, similarly aged, hospitalized patients without diarrhoea to estimate the prevalence of STEC asymptomatic colonization, and to use a sensitive technique to screen stools for STEC (DNA extraction from stool, followed by PCR for toxin genes), a strategy used in many other countries for STEC surveillance.

A recent review of STEC in India (Khan et al., 2002) concluded that although STEC reservoirs exist and the organism is clearly present in the food chain and the environment, human STEC disease appears to be infrequent in India. Our study provides confirmation of the low incidence of STEC in diarrhoeal stools from preschool-aged children admitted to hospital in South India, and shows that, as with other enteric pathogens, there is asymptomatic colonization with STEC in preschool-aged children. Further work should focus on the incidence of STEC infection in the preschool-aged outpatient population, on correlates of protective immunity in the asymptomatically colonized, and on the epidemiological and evolutionary relationships between STEC that is present in the environment, cattle and/or the food chain, and STEC that is ultimately acquired by humans.

\section{Priya Rajendran, ${ }^{1}$ \\ Deva Prasanna Rajan, ${ }^{1}$ Gagandeep Kang ${ }^{1}$ and Cheleste M. Thorpe ${ }^{2}$}

\section{${ }^{1}$ Department of Gastrointestinal Sciences, Christian Medical College, Vellore, India \\ ${ }^{2}$ Division of Geographic Medicine and Infectious Diseases, Tufts Medical Center, Boston, USA}

Correspondence: Cheleste M. Thorpe (cthorpe@tuftsmedicalcenter.org)

Boerlin, P., McEwen, S. A., Boerlin-Petzold, F., Wilson, J. B., Johnson, R. P. \& Gyles, C. L. (1999). Associations between virulence factors of Shiga toxin-producing Escherichia coli and disease in humans. J Clin Microbiol 37, 497-503.

Dhanashree, B. \& Mallya, P. S. (2008). Detection of shiga-toxigenic Escherichia coli (STEC) in diarrhoeagenic stool \& meat samples in Mangalore, India. Indian J Med Res 128, 271-277. 
Table 1. Characteristics of STEC strains isolated from children with diarrhoea in South India

\begin{tabular}{|llcccc|}
\hline Isolate & Source & stx 1 & stx2 & eae & subAB \\
\hline Cases & & & & & \\
RV 207 & Diarrhoea & + & - & + & - \\
RV 252 & Diarrhoea & + & - & - & - \\
RV 315 & Diarrhoea & + & - & - & - \\
RV 346 & Diarrhoea & + & - & + & - \\
ICRV 21 & Diarrhoea & - & + & + & - \\
ICRV 29 & Diarrhoea & - & + & + & - \\
ICRV 48 & Diarrhoea & + & - & - & - \\
ICRV 88 & Diarrhoea & + & - & - & - \\
ICRV 153 & Diarrhoea & + & - & - & - \\
Controls & & & & & - \\
CH3 79 & Control & - & + & + & - \\
CH3 85 & Control & + & - & + & \\
\hline
\end{tabular}

Donnenberg, M. S., Tzipori, S., McKee, M. L., O’Brien, A. D., Alroy, J. \& Kaper, J. B. (1993).

The role of the eae gene of enterohemorrhagic Escherichia coli in intimate attachment in vitro and in a porcine model. J Clin Invest 92, 14181424.

Khan, A., Yamashiki, S., Sato, T., Ramamurthy, T., Pal, A., Datta, S., Chowdhry, N. R., Das, S. C.,
Sikadar, A. \& other authors (2002). Prevalence and genetic profiling of virulence determinants of non-157 Shiga toxin-producing Escherichia coli isolated from cattle, beef and humans, Calcutta, India. Emerg Infect Dis 8, 54-62.

Monica, B., Ramani, S., Banerjee, I., Primrose, B., Iturriza-Gomara, M., Gallimore, C. I., Brown, D. W., M, F., Moses, P. D. \& other authors (2007). Human caliciviruses in symptomatic and asymptomatic infections in children in Vellore, South India. J Med Virol 79, 544-551.

Paton, A. W. \& Paton, J. C. (2005). Multiplex PCR for direct detection of Shiga toxigenic Escherichia coli strains producing the novel subtilase cytotoxin. J Clin Microbiol 43, 2944-2947.

Tozzi, A. E., Caprioli, A., Minelli, F., Gianviti, A., De Petris, L., Edefonti, A., Montini, G., Ferretti, A., De Palo, T. \& other authors (2003). Shiga toxin-producing Escherichia coli infections associated with hemolytic uremic syndrome, Italy, 1988-2000. Emerg Infect Dis 9, 106-108.

Uhlich, G. A., Sinclair, J. R., Warren, N. G., Chmielecki, W. A. \& Fratamico, P. (2008).

Characterization of Shiga toxin-producing Escherichia coli isolates associated with two multistate food-borne outbreaks that occurred in 2006. Appl Environ Microbiol 74, 1268-1272.

Vidal, M., Kruger, E., Duran, C., Lagos, R., Levine, M., Prado, V., Toro, C. \& Vidal, R. (2005). Single multiplex PCR assay to identify simultaneously the six categories of diarrheagenic Escherichia coli associated with enteric infections. J Clin Microbiol 43, 5362-5365. 